\title{
Case report of first-episode psychotic symptoms in a patient with early-onset Alzheimer's disease
}

\author{
Xiao $\mathrm{Li}^{1 \dagger}$, Zhenzhen Xiong ${ }^{2 \dagger}$, Yaya Liu ${ }^{1,3}$, Yiwen Yuan ${ }^{1}$, Junfeng Deng ${ }^{1}$, Weiyi Xiang ${ }^{4}$ and Zhe $\mathrm{Li}^{1^{*}}$
}

\begin{abstract}
Background: Alzheimer's disease (AD) is a neurodegenerative disorder featuring the behavioral and psychological symptoms of dementia. Patients with early-onset AD that exhibits first as psychotic symptoms usually lack obvious cognitive impairment, so they may be misdiagnosed with late-onset schizophrenia.

Case presentation: We report a patient who had prominent psychotic symptoms at the age of 60 and was initially diagnosed with very-late-onset-schizophrenia-like psychosis. Psychotic symptoms disappeared rapidly after treatment with olanzapine, and the patient later showed extrapyramidal symptoms and decline in cognitive function. Brain magnetic resonance imaging (MRI) showed frontotemporal atrophy, and positron emission tomography (PET) showed extensive areas of hypometabolism in the frontal cortex and head of the caudate nucleus. The patient's SORL1 gene was found to carry a heterozygrous mutation (c.296A > G). The patient was eventually diagnosed with early-onset AD.

Conclusions: Our case suggests that clinicians should consider the possibility of early-onset AD in middle-aged or elderly patients whose first symptoms are the behavioral and psychological symptoms of dementia. To distinguish early-onset AD from late-onset schizophrenia, clinicians should evaluate cognitive function, perform MRI and PET, and search for SORL1 mutations.
\end{abstract}

Keywords: Brain imaging, Cognitive function, Dementia, Schizophrenia, SORL1

\section{Background}

Alzheimer's disease (AD) is a common neurodegenerative disorder characterized by progressive cognitive impairment $[1,2]$. In 2010, AD affected 4.7 million individuals in the US alone and by 2050 an estimated 13.8 million people may have AD in the US [3]. It was reported that the prevalence of $\mathrm{AD}$ is $3.21 \%$ among individuals aged 65 years and older in China [4], which poses a huge challenge and burden for elderly, families,

\footnotetext{
*Correspondence: jay_li@163.com

${ }^{+}$Xiao Li and Zhenzhen Xiong contributed equally to this work.

${ }^{1}$ Mental Health Center and National Clinical Research Center for Geriatrics,

West China Hospital, Sichuan University, No. 28 Dian Xin Nan Road, Chengdu 610041, Sichuan, China

Full list of author information is available at the end of the article
}

caregivers and wider society. Because $\mathrm{AD}$ is chronic, early identification and intervention are important to improve prognosis.

$\mathrm{AD}$ is typically classified as early-onset if it occurs before the age of 65 , or late-onset if it occurs later [5]. The early-onset form of the disease accounts for only $5.5 \%$ of all AD cases, so it is often overlooked [6]. The behavioral and psychological symptoms of dementia (BPSD) including agitation, aggression, apathy, depression, psychosis, disinhibition can occur early in $\mathrm{AD}$, even before the onset of dementia $[7,8]$. It can be challenging to distinguish between BPSD in AD and other mental disorders, such as major depressive disorder or schizophrenia, especially very late-onset schizophrenia-like psychosis (VLOSLP). This type of psychosis, which shows a

(c) The Author(s). 2020 Open Access This article is licensed under a Creative Commons Attribution 4.0 International License, which permits use, sharing, adaptation, distribution and reproduction in any medium or format, as long as you give appropriate credit to the original author(s) and the source, provide a link to the Creative Commons licence, and indicate if changes were made. The images or other third party material in this article are included in the article's Creative Commons licence, unless indicated otherwise in a credit line to the material. If material is not included in the article's Creative Commons licence and your intended use is not permitted by statutory regulation or exceeds the permitted use, you will need to obtain permission directly from the copyright holder. To view a copy of this licence, visit http://creativecommons.org/licenses/by/4.0/ The Creative Commons Public Domain Dedication waiver (http://creativecommons.org/publicdomain/zero/1.0/) applies to the data made available in this article, unless otherwise stated in a credit line to the data. 
community prevalence of $0.1-0.5 \%$ [9], generally occurs after the age of 60 and is characterized by psychotic symptoms such as delusions and hallucinations. Patients with VLOSLP usually have psychotic symptoms and mild cognitive deficits, so they may be misdiagnosed as having dementia [10]. Patients in early stages of AD may manifest only behavioral and psychological symptoms of dementia without obvious decline in cognitive function, so they may be misdiagnosed with VLOSLP.

Mutations in the SORL1 gene, which encodes a protein involved in the processing of amyloid-beta $(\mathrm{A} \beta)$ precursor protein and in secretion of the $A \beta$ peptide, have been associated with $\mathrm{AD}$ [11]. The potential role of these mutations in the disease has been neglected in favor of studies of much more frequent mutations in such genes as APP, PSEN1 and PSEN2 [12] .

Here we present a patient with $\mathrm{AD}$ and SORL1 mutations whose first-episode psychotic symptoms occurred before the age of 65 and who was initially misdiagnosed with schizophrenia. To the best of our knowledge, this is the first report of a patient with early-onset $\mathrm{AD}$ whose first symptoms were psychotic and extrapyramidal.

\section{Case presentation}

A right-handed, 63-year-old Chinese woman, with 12 years of education, was admitted to our hospital in September 2018 at the request of her family members.

\section{History of presenting complaint}

In 2016, the patient had developed psychotic symptoms, including delusions and auditory hallucination, without an apparent cause. She said someone wanted to harm her and was talking about her. Sometimes she told her family members that she heard knocking on the door, and she exhibited diminished emotional expression and avolition. She required the support of family members to conduct daily activities and communicate with others. Her sleep quality was poor, but she showed no disturbance of consciousness. She did not seek medical advice and receive any remedy at that time.

After these symptoms had continued for about 12 months, she was taken by her family to the outpatient department of our hospital. Brain magnetic resonance imaging (MRI) did not reveal any obvious structural abnormalities (Fig. 1). She was diagnosed with schizophrenia by an experienced psychiatrist based on criteria in the fifth edition of the Diagnostic and Statistical Manual of Mental Disorders [13]. Delusions and hallucinations disappeared after the patient took $5 \mathrm{mg}$ of olanzapine every night for 1 month. We monitored the blood glucose, blood lipid, blood pressure and weight every month to investigate the possibility of metabolic syndrome after treatment with olanzapine. However, she began to walk slowly, her neck became rigid, and she experienced episodic memory impairment, leading her to forget new events, ask the same question repeatedly and get lost in new places. Her physical functions, such as dressing and eating, were also impaired. However, she did not develop language dysfunction, and she was able to communicate smoothly with family members. She was treated with benzhexol hydrochloride at $2 \mathrm{mg}$ every night for extrapyramidal symptoms, but the symptoms did not improve. The daily dose of olanzapine was reduced to $2.5 \mathrm{mg}$ in July 2017, but the symptoms still did not improve after 1 month. Therefore, we believe that her symptoms did not cause by olanzapine then stop using benzhexol hydrochloride.

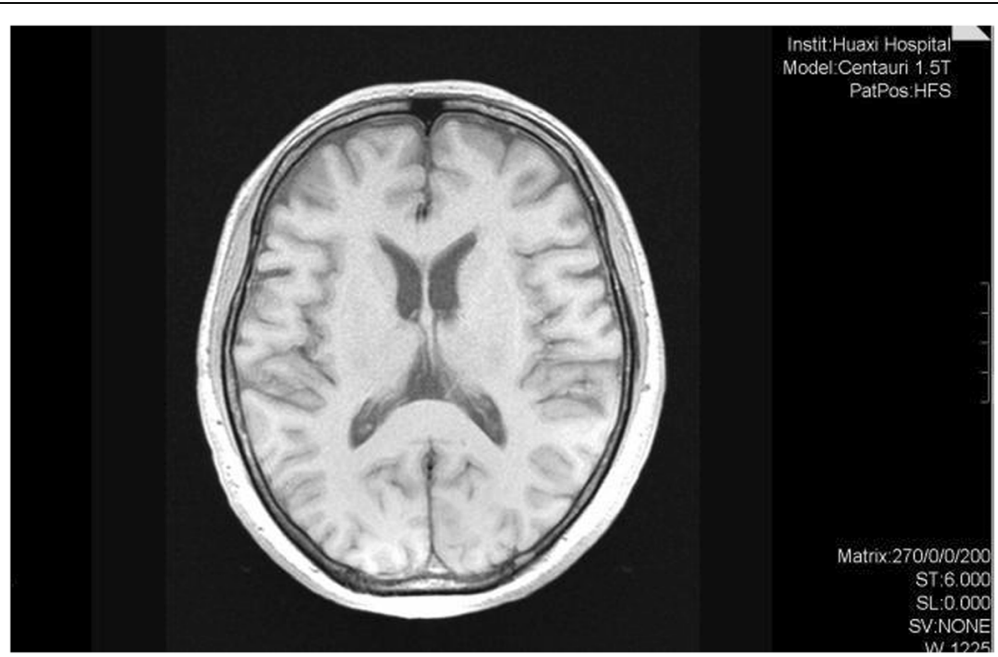

Fig. 1 Brain MRI in 2016. No structural abnormality has been found 
In May 2018, her neck stiffness became worse and gradually spread to the limbs. She developed severe neck, limb and postural rigidity, but no tremor. She walked unstably, exhibited bradykinesia and memory decline, and showed obvious decline in her ability to take care of herself. On the other hand, she did not exhibit socially inappropriate behaviors, apathy, or dietary changes, and she responded normally to family members' feelings.

At her admission to our hospital in September 2018, the patient reported never smoking or drinking. She had previously undergone gallbladder surgery. She was in good health and had no family history of mental disorders. The patient had good support from family members and did not report any major adverse life events. The patient and her family members denied any drug abuse. She did not have any history of violence, agitation and suicidal behavior during the course of her illness. Her vital signs were stable, and no abnormal physical signs were detected at admission. Blood and urine tests, blood glucose level, liver and renal function and thyroid function were normal, and the patient showed no evidence of infection. Electroencephalography, electrocardiography, and transcranial doppler ultrasound results were normal. Mental status examination showed no signs of hallucinations or delusions. The patient had stable mood but temporal disorientation and deficits in attention, calculation and language competence, as well as delayed recall. She also exhibited impairments in visuospatial organization and abstract thinking. She had no insight into her disease. The total score on the MMSE was 16 and on the MoCA was 9.
During hospitalization, brain MRI showed mild frontotemporal atrophy relative to the MRI in 2016 (Fig. 2). She scored 16/30 on the Mini-Mental State Exam (MMSE). She exhibited temporal disorientation and deficits in attention, calculation and language competence, as well as delayed recall. She scored 9/30 on the Montreal Cognitive Assessment (MoCA), indicating impairments in visuospatial organization, attention, language ability, temporal orientation, and abstract thinking. Her total score on the Activity of Daily Living Scale (ADL) [14] was 54, indicating difficulty in performing daily life activities (Table 1). Based on her two-year history of using antipsychotics and hypermyotonia, she was diagnosed with tardive dyskinesia. After consultation with experts in the neurology department, her diagnosis was changed to Parkinson's disease on the basis of her bradykinesia and hypermyotonia. Olanzapine treatment was replaced with the combination of levodopa and benserazide hydrochloride $(375 \mathrm{mg} / \mathrm{d})$, pramipexole hydrochloride $(0.75 \mathrm{mg} / \mathrm{d})$, Selegiline hydrochloride $(5 \mathrm{mg} / \mathrm{d})$, and benzhexol hydrochloride $(3 \mathrm{mg} / \mathrm{d})$. Her bradykinesia, rigidity and shuffling gait improved after 2 weeks, but not her memory. She was discharged in October 2018.

\section{Follow up/reviews}

During a follow-up visit 2 months after discharge, 53 genes associated with dementia were analyzed (Table 2). The only mutation detected was a heterozygous variant in SORL1 (chr11:121340726, c.296A > G). She showed a higher score of 20/30 on both the MMSE and MoCA. She was prescribed with memantine $(10 \mathrm{mg} / \mathrm{d})$ and

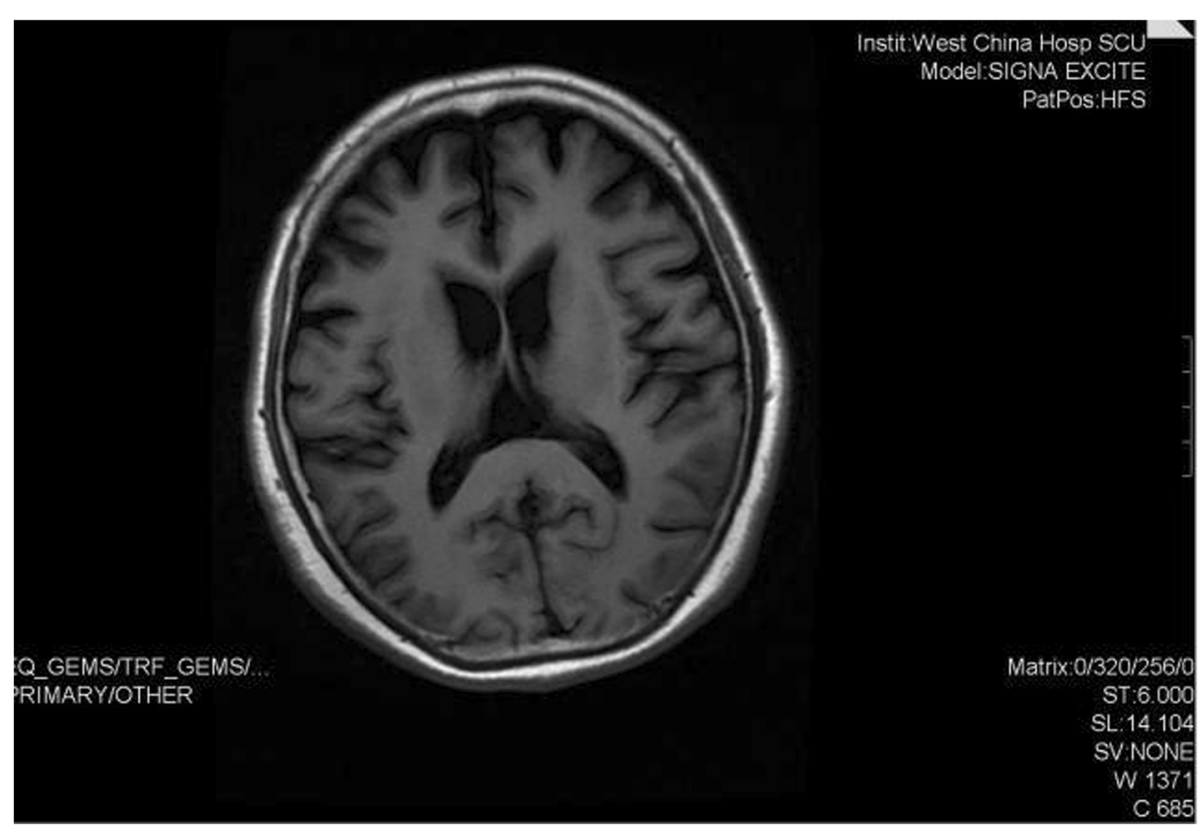

Fig. 2 The brain MRI in September 2018. Brain MRI showed mild bilateral frontotemporal atrophy 
Table 1 Scores of Activity of Daily Living (ADL) scale in 2018

\begin{tabular}{llll}
\hline Item & Score & Item & Score \\
\hline Transportation & 4 & Personal hygiene & 4 \\
Walking & 4 & Washing & 4 \\
Food preparation & 4 & Bath/shower & 4 \\
Housework & 4 & Shopping & 4 \\
Medication & 3 & Toilet/commode & 4 \\
Eating & 3 & Telephone & 4 \\
Dressing & 4 & Finances & 4 \\
\hline
\end{tabular}

Note: Each item gets 1 point for normal. The score of $2-4$ points represent function decline in each item

donepezil $(10 \mathrm{mg} / \mathrm{d})$ and stopped taking benzhexol hydrochloride, but her cognitive function showed no change at follow-up in July 2019. At follow-up in August 2019, brain MRI detected moderate frontotemporal atrophy that appeared more serious than in 2018 (Fig. 3), while ${ }^{18}$ F-fluorodeoxyglucose-based positron emission tomography/computed tomography demonstrated bilateral frontal and caudate hypometabolism (Fig. 4). The score on MoCA improved to 23/30, but the score on the ADLS fell to 31 . She was unable to complete many daily life activities (Table 3).

Our patient was diagnosed with probable AD because of early, significant episodic memory impairment, medial temporal lobe atrophy, brain glucose hypometabolism based on PET and AD-associated genetic mutation [15]. She was prescribed memantine $(10 \mathrm{mg} / \mathrm{d})$ and donepezil $(10 \mathrm{mg} / \mathrm{d})$. At her last follow-up in October 2019, the patient showed poor memory, slow reaction and bradykinesia, but no psychotic symptoms.

\section{Diagnostic symptoms}

\section{Alzheimer's disease}

The patient had temporal disorientation and deficits in attention, calculation and language competence, significant episodic memory impairment. She had significant temporal lobe atrophy, brain glucose hypometabolism based on PET and AD-associated genetic mutation. A timeline of the historical and current information is shown in Fig. 5.

\section{Differential diagnostic symptoms VLOSLP}

The psychotic symptoms of the patient occur after the age of 60, but disappeared after treatment with antipsychotics in 1 month. She did not display the clinical course typical of patients with schizophrenia. Frontotemporal dementia: The patient did not display the impaired language function typical of semantic variant primary progressive aphasia or the non-fluent/agrammatic variant of primary progressive aphasia $[16,17]$. She also did not display early behavioral disinhibition, apathy, loss of sympathy or empathy, dietary changes, or deficits in executive tasks typical of the behavioral variant of frontotemporal dementia [18].

\section{Discussion and conclusions}

To the best of our knowledge, this is the first report of an AD patient with mutations in the SORL1 gene who presented initially psychotic symptoms before 65 years old, but she was misdiagnosed with schizophrenia. 1 month after treatment with antipsychotics, her psychotic symptoms disappeared, but she began to experience rigidity, bradykinesia, and impaired cognitive function. She did not display the clinical course typical of patients with schizophrenia. These considerations, combined with results from neuropsychological examinations, brain MRI, fluorodeoxyglucose PET and gene mutation analysis, led us to diagnose the patient with early-onset AD.

$\mathrm{AD}$ is the most common cause of dementia and is characterized by the presence of $\mathrm{A} \beta$ plaques and taucontaining neurofibrillary tangles in the brain [19]. Many AD patients eventually display behavioral and psychological symptoms of dementia, which include four neuropsychiatric sub-symptoms: hyperactivity, psychosis, affective symptoms and apathy [20]. A population-based study of Chinese elderly with dementia found that half had at least one behavioral or psychological symptom of dementia [21]. Psychiatric symptoms are commonly seen in the early stage of dementia and can be present at all stages of disease, but rarely seen in early-onset $\mathrm{AD}[22,23]$. Behavioral

Table 2 A list of genes analyzed

\begin{tabular}{|c|c|c|c|c|c|c|c|}
\hline \\
\hline \multicolumn{8}{|c|}{$\frac{\text { Gene Analyzed }}{\text { A2M }}$} \\
\hline ATP13A2 & $\mathrm{BCHE}$ & C9orf72 & CHMP2B & CHRM1 & CLU & CR1 & DNMT1 \\
\hline FAM134B & GBA & GRN & GSTO1 & HFE & HNRNPA1 & HNRNPA2B1 & ITM2B \\
\hline KLK1 & LOC643387 & MAPT & MEOX2 & MPO & NOS3 & NOTCH3 & NPC1 \\
\hline PAXIP1 & PICALM & PLAU & PLD3 & PRNP & PSEN1 & PSEN2 & RPS27A \\
\hline SLC6A4 & SNCA & SNCB & SORL1 & SQSTM1 & TARDBP & TBK1 & TNFSF14 \\
\hline TREM2 & TRPM7 & TYROBP & UBQLN2 & VCP & & & \\
\hline
\end{tabular}




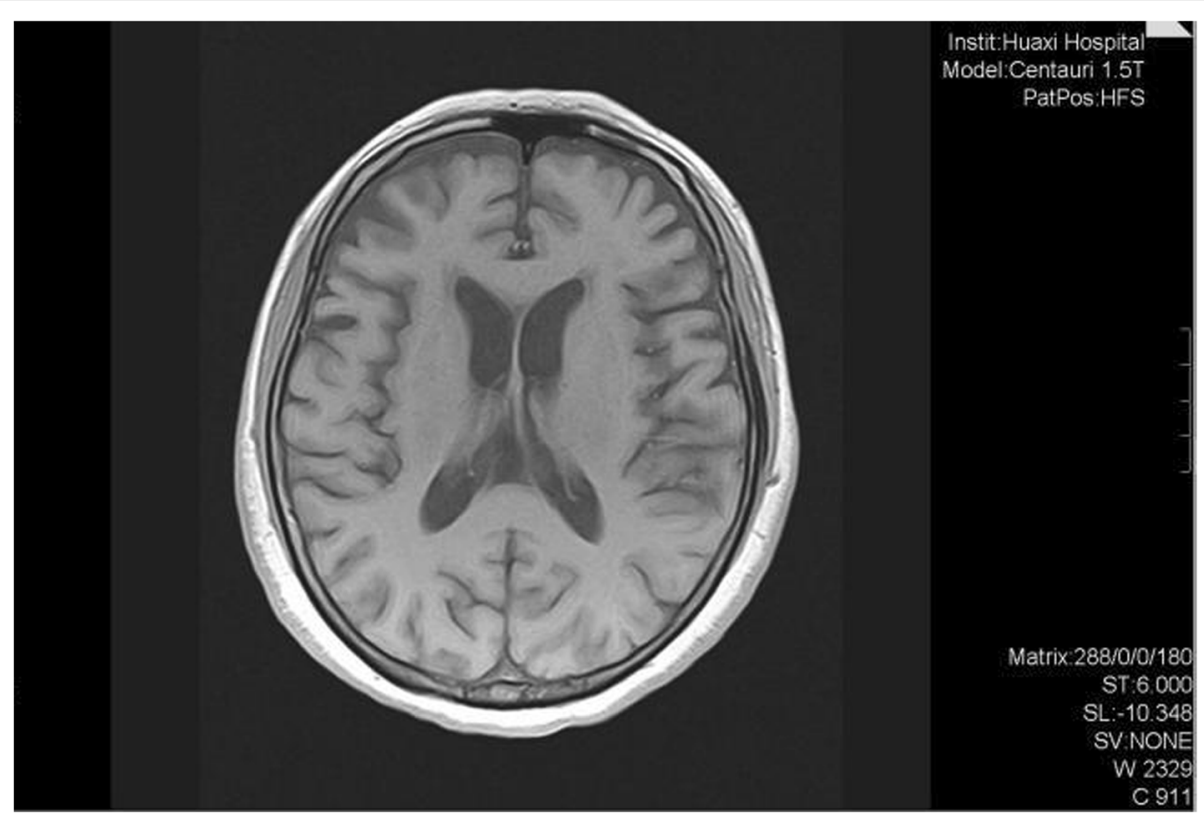

Fig. 3 The brain MRI in August 2019. Brain MRI Showed moderate bilateral frontotemporal atrophy

and psychological symptoms of dementia in $\mathrm{AD}$ can increase the cost of health care, reduce quality of life, lead to long-term hospitalization and place an enormous burden on caregivers [24]. Therefore, early identification and treatment of such symptoms can help improve the prognosis of $\mathrm{AD}$ patients.

The patient experienced the symptoms of rigidity, bradykinesia and cognitive decline after olanzapine treatment. Although olanzapine can cause extrapyramidal symptoms such as those observed in our patient [25], we believe that the drug was not the cause in our patient. Olanzapine is associated with lower incidence of such symptoms than first-generation antipsychotics [26], and the symptoms in our patient did not improve when the olanzapine dose was reduced or when the drug was replaced with benzhexol hydrochloride. We hypothesize that the extrapyramidal symptoms in our patient were part of the manifestations of $\mathrm{AD}$ with parkinsonian symptoms. These symptoms are observed in many patients with $\mathrm{AD}$, and they are associated with reduced ability to perform daily activities and with severe cognitive impairment, including attention and visuospatial deficit [27, 28]. In a longitudinal study has also found that progressive worsening of parkinsonism is strongly associated with cognitive decline in AD patients [29]. Screening for such symptoms may allow early detection of $\mathrm{AD}$, and these symptoms may be useful as a prognostic marker for predicting cognitive function [28]. In early $A D$, extrapyramidal symptoms have also been associated with pathological changes in substantia nigra, including $\alpha$-synuclein aggregation, hyperphosphorylated tau accumulation, and neuronal loss [30].

Our previous work has linked the following 21 well-studied genes with AD: TGFB1, CTNNB1, APP, IL1B, PSEN1, PTGS2, IL6, VEGFA, SOD1, AKT1, CDK5, TNF, GSK3B, TP53, CCL2, BDNF, NGF, IGF1, SIRT1, AGER and TLR [31]. Other work has also linked mutations in APP, PSEN1 and PSEN2 with early-onset AD [12]. Although we analyzed 53 genes associated with dementia, our patient showed a mutation only in the SORL1 gene. The SORL1 gene encodes a protein involved in the processing of amyloid-beta $(A \beta)$ precursor protein and in secretion of the $A \beta$ peptide. The SORL1 has been found to be associated with age-related cognitive decline in episodic memory and processing speed in non-demented older adults [32]. The mutations in this gene have also been reported in $\mathrm{AD}$, they appear to play a critical role in the disease [11] and may even be a risk factor for the early-onset form [33], consistent with the role of SORL1 in $\mathrm{A} \beta$ processing and secretion. Therefore, the early cognitive decline of our patients including temporal disorientation, deficits in attention, calculation and language competence, significant episodic memory impairment may associate with the mutations in this gene.

The previous study indicated that the mutations in SORL1 gene are associated with parkinsonian features in AD patients, such as tremor at rest, hypophonia, micrographia, masked facial expression, smaller steps on gait, 


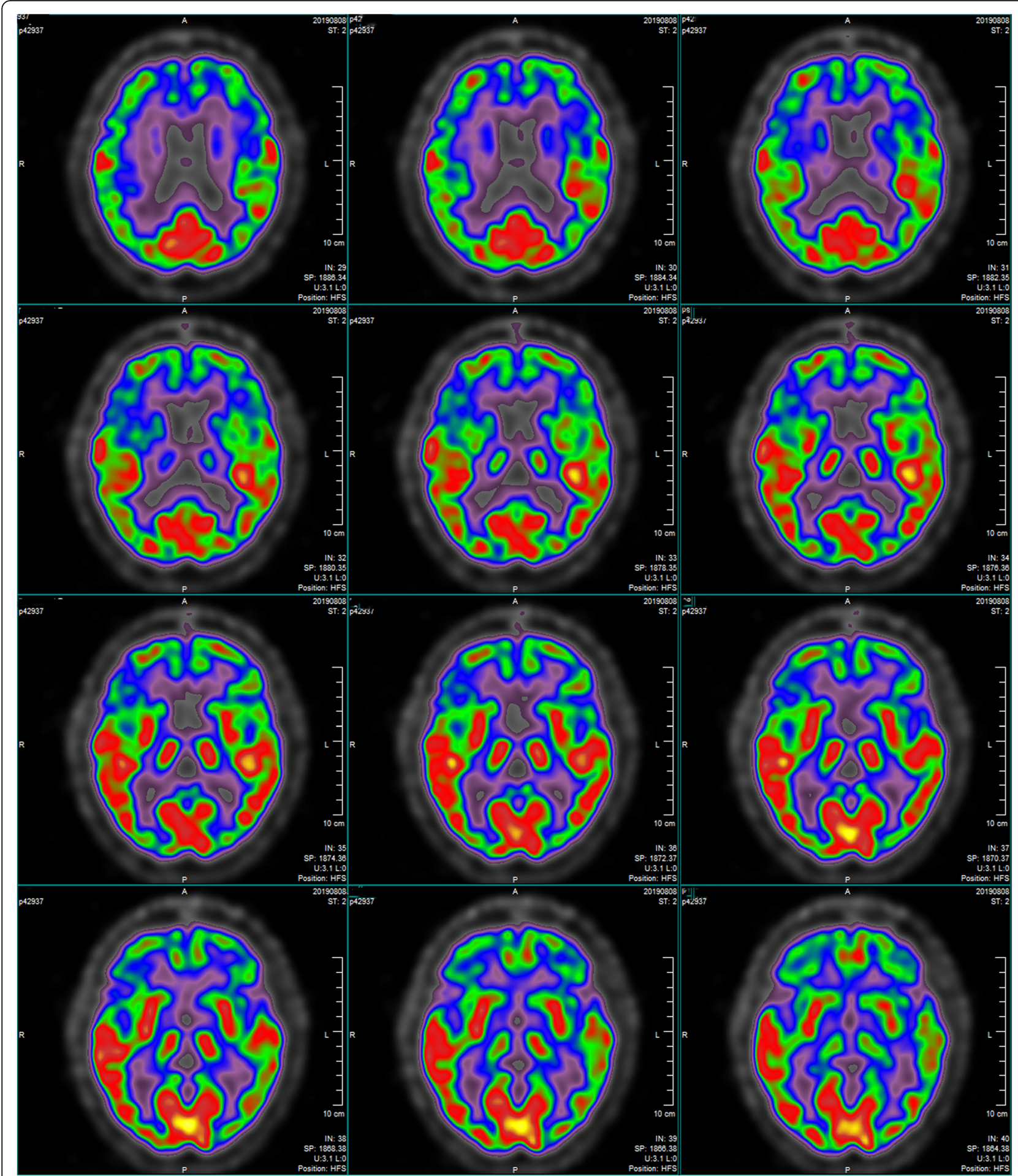

Fig. 4 The 18F-FDG PET/CT in August 2019. Extensive areas of hypometabolism in frontal cortex and head of caudate nucleus

and overall bradykinesia [34]. In addition, the SORL1 variations are found to influence the brain structure. A structural MRI study in Chinese population has found the SORL1 variants are associated with grey matter volume (GMV) reduction of the right middle temporal pole in older adults [32]. Another brain structural study in Chinese population has found individuals carrying SORL1 allele A showing reduced grey matter volumes in the right posterior cingulate, left middle occipital, medial frontal, and superior temporal gyri [35]. These results 
Table 3 Scores of Activity of Daily Living (ADL) scale in 2019

\begin{tabular}{llll}
\hline Item & Score & Item & Score \\
\hline Transportation & 3 & Personal hygiene & 1 \\
Walking & 3 & Washing & 3 \\
Food preparation & 2 & Bath/shower & 3 \\
Housework & 3 & Shopping & 2 \\
Medication & 3 & Toilet/commode & 2 \\
Eating & 1 & Telephone & 1 \\
Dressing & 3 & Finances & 1 \\
\hline
\end{tabular}

Note: Each item gets 1 point for normal. The score of 2-4 points represent function decline in each item

suggested that the SORL1 variants have an effect on brain structure. Our patient had frontotemporal lobe atrophy, this brain structural alterations might associate with SORL1 gene mutation. Therefore, the SORL1 gene mutation could lead to the development and progression of cognitive decline, parkinsonian motor symptoms and brain structural alterations. Screening for SORL1 mutations may be useful for patients suspected of having early-onset AD.

Our patient had frontotemporal lobe atrophy, but not frontotemporal dementia. She did not display the impaired language function typical of semantic variant primary progressive aphasia or the non-fluent/agrammatic variant of primary progressive aphasia $[16,17]$. She also did not display early behavioral disinhibition, apathy, loss of sympathy or empathy, dietary changes, or deficits in executive tasks typical of the behavioral variant of frontotemporal dementia [18]. These considerations, combined with the fact that SORL1 mutation has not been associated with frontotemporal dementia, led us to favor a diagnosis of early-onset AD. A recent neuroimaging study has found that the volumes of frontal, temporal and other brain regions can predict the behavioral and psychological symptoms in $\mathrm{AD}$, and the frontal lobe volume was the most powerful predictor [36]. Therefore, the frontotemporal lobe atrophy of this patient may associate with the early onset of behavioral and psychological symptoms.

There is an overlapping syndrome with diffuse brain structural, metabolic changes, cognitive decline and parkinsonian motor symptoms related to SORL1 gene mutation. Early-onset AD should be considered when a patient initially presenting psychotic symptoms and SORL1 gene mutation is older than the typical age of schizophrenia onset. Our patient was initially misdiagnosed with schizophrenia because of misattribution of the behavioral and psychological symptoms of dementia. We suggest that diagnosis of middle-aged or elderly patients with behavioral and psychological symptoms of dementia as the first presentation should involve detailed cognitive function assessment, brain MRI and PET, and analysis of mutations in $\mathrm{AD}$-associated genes.

\section{Abbreviations}

AD: Alzheimer's disease; MRI: Magnetic resonance imaging; PET: Positron emission tomography; VLOSLP: Very late-onset schizophrenia-like psychosis; Aß: Amyloid-beta; MMSE: Mini-mental state exam; MoCA: Montreal cognitive assessment; ADL: Activity of daily living; GMV: Grey matter volume

\section{Acknowledgements}

The authors would like to thank all of their coworkers of West China Hospital, National Clinical Research Center for Geriatrics, School of Nursing,

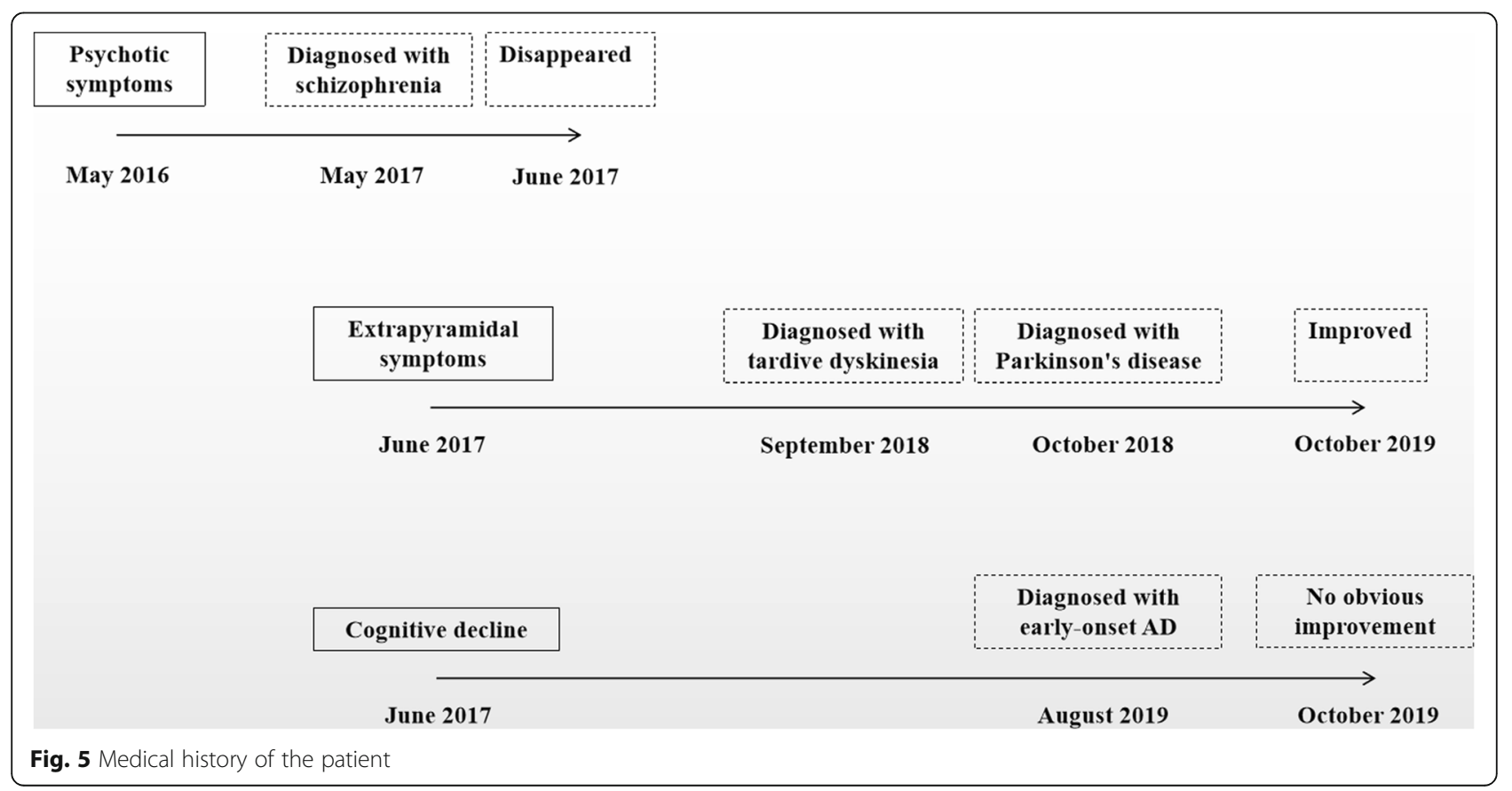


Chengdu Medical College, Zun Yi Psychiatric Hospital, and The West China College of Medicine on this case for their skillful contributions.

\section{Authors' contributions}

$\mathrm{XL}$ and ZZX treated this patient, completed the paper and contributed equally to this work. $Y Y L$ and $Y W Y$ conducted follow-up of this patient. JFD and WYX conducted cognitive, MRI and PET assessment. ZL critically reviewed the diagnostic results and contributed to the preparation and revision of the manuscript. All authors read and approved the final version of the manuscript.

\section{Funding}

This work was partly funded by Science and Technology Department of Sichuan Province (2017SZ0049, Zhe Li), Health Commission of Sichuan Province (19PJ187, Zhenzhen Xiong), The Project of Chengdu Medical College Curriculum Case Base Construction for Professional Dgree Postgraduate (CYAL-201907, Zhenzhen Xiong) and National Steering Committee for Medical Professional Degree Education (Medical and Pharmaceutical Committee for Chinese Society of Academic Degrees and Graduate Education) (C-YX20190302-02, Zhenzhen Xiong).

\section{Availability of data and materials}

This is a single-patient case report. Data sharing is not applicable to this article as no datasets besides those mentioned in the article were generated or analysed.

\section{Ethics approval and consent to participate}

Written informed consent was obtained from the patient and her husband for the case report. West China Hospital Ethics Committee approved the study.

\section{Consent for publication}

The patient's husband and daughter received a complete description of the report and provided written informed consent. A copy of the written consent is available for review by the editor of this journal.

\section{Competing interests}

The authors declare that they have no competing interests.

\section{Author details}

${ }^{1}$ Mental Health Center and National Clinical Research Center for Geriatrics, West China Hospital, Sichuan University, No. 28 Dian Xin Nan Road, Chengdu 610041, Sichuan, China. ${ }^{2}$ School of Nursing, Chengdu Medical College, Chengdu 610083, Sichuan, China. ${ }^{3}$ Zun Yi Psychiatric Hospital, Zunyi 563000, Guizhou, China. ${ }^{4}$ The West China College of Medicine, Sichuan University, Chengdu 610041, Sichuan, China.

\section{Received: 27 December 2019 Accepted: 6 March 2020} Published online: 17 March 2020

\section{References}

1. Giau W, Bagyinszky E, An SSA, Kim S. Clinical genetic strategies for early onset neurodegenerative diseases. Mol Cell Toxicol. 2018;14(2):123-42.

2. Wilson RS, Segawa E, Boyle PA, Anagnos SE, Hizel LP, Bennett DA. The natural history of cognitive decline in Alzheimer's disease. Psychol Aging. 2012;27(4):1008-17.

3. Hebert LE, Weuve J, Scherr PA, Evans DA. Alzheimer disease in the United States (2010-2050) estimated using the 2010 census. Neurology. 2013;80(19):1778-83.

4. Jia J, Wang F, Wei C, Zhou A, Jia X, Li F, Tang M, Chu L, Zhou Y, Zhou C, et al. The prevalence of dementia in urban and rural areas of China. Alzheimers Dement. 2014;10(1):1-9.

5. Mendez MF. Early-onset Alzheimer disease. Neurol Clin. 2017;35(2):263-81.

6. Zhu XC, Tan L, Wang HF, Jiang T, Cao L, Wang C, Wang J, Tan CC, Meng XF, Yu JT. Rate of early onset Alzheimer's disease: a systematic review and meta-analysis. Ann Transl Med. 2015;3(3):38.

7. Kasuga K, Ohno T, Ishihara T, Miyashita A, Kuwano R, Onodera O, Nishizawa M, Ikeuchi T. Depression and psychiatric symptoms preceding onset of dementia in a family with early-onset Alzheimer disease with a novel PSEN1 mutation. J Neurol. 2009;256(8):1351-3.
8. Gerlach LB, Kales HC. Managing behavioral and psychological symptoms of dementia. Psychiatr Clin North Am. 2018;41(1):127-39.

9. Robert Howard MDPV. Late-onset schizophrenia and very-late-onset schizophrenia-like psychosis: An international consensus. Am J Psychiatry. 2000;157:172-8.

10. Lies Van Assche MMPL. The neuropsychology and neurobiology of lateonset schizophrenia and very-late-onset schizophrenia-like psychosis: a critical review. Neurosci Biobehav Rev. 2017;83:604-21.

11. Campion D, Charbonnier C, Nicolas G. SORL1 genetic variants and Alzheimer disease risk: a literature review and meta-analysis of sequencing data. Acta Neuropathol. 2019;138(2):173-86.

12. Giau W, Bagyinszky E, Youn YC, An SSA, Kim S. APP, PSEN1, and PSEN2 mutations in Asian patients with early-onset Alzheimer disease. Int J Mol Sci. 2019;20(19):4757.

13. American Psychiatric Association. Diagnostic and statistical manual of mental disorder. Arlington: American Psychiatric Publishing; 2013. p. 5.

14. Lawton MP, Brody EM. Assessment of older people: self-maintaining and instrumental activities of daily living. Gerontologis0074. 1969;9(3):179-86.

15. Dubois BM, Feldman HHM, Jacova CP, DeKosky STM, Barberger-Gateau PM, Cummings JM, Delacourte AP, Galasko DM, Gauthier SM, Jicha GM, et al. Research criteria for the diagnosis of Alzheimer's disease: revising the NINCDS-ADRDA criteria. Lancet Neurol. 2007;6(8):734-46.

16. Lima BSLBGN. Impaired coherence for semantic but not episodic autobiographical memory in semantic variant primary progressive aphasia. Cortex. 2019;123:72-85.

17. Grossman M. The non-fluent/agrammatic variant of primary progressive aphasia. Lancet Neurol. 2012;11(6):545-55.

18. Rascovsky K, Hodges JR, Knopman D, Mendez MF, Kramer JH, Neuhaus J, van Swieten JC, Seelaar H, Dopper EGP, Onyike CU, et al. Sensitivity of revised diagnostic criteria for the behavioural variant of frontotemporal dementia. Brain. 2011;134(9):2456-77.

19. Vinters HV. Emerging concepts in Alzheimer's disease. Annu Rev Pathol. 2015;10(1):291-319.

20. Aalten P, Verhey FRJ, Boziki M, Bullock R, Byrne EJ, Camus V, Caputo M, Collins D, De Deyn PP, Elina K, et al. Neuropsychiatric syndromes in dementia. Results from the European Alzheimer disease consortium: part I. Dement Geriatr Cogn Disord. 2007;24(6):457-63.

21. Haibo X, Shifu X, Pin NT, Chao C, Guorong M, Xuejue L, Shiming B, Wenli F, Jun L, Mingyuan Z, et al. Prevalence and severity of behavioral and psychological symptoms of dementia (BPSD) in community dwelling Chinese: findings from the Shanghai three districts study. Aging Ment Health. 2013;17(6):748-52.

22. Gottesman RT, Stern Y. Behavioral and psychiatric symptoms of dementia and rate of decline in Alzheimer's disease. Front Pharmacol. 2019;10:1062.

23. Ismail Z, Smith EE, Geda Y, Sultzer D, Brodaty H, Smith G, Agüera-Ortiz L, Sweet R, Miller D, Lyketsos CG. Neuropsychiatric symptoms as early manifestations of emergent dementia: provisional diagnostic criteria for mild behavioral impairment. Alzheimers Dement. 2016;12(2):195-202.

24. Baharudin AD, Din NC, Subramaniam P, Razali R. The associations between behavioral-psychological symptoms of dementia (BPSD) and coping strategy, burden of care and personality style among low-income caregivers of patients with dementia. BMC Public Health. 2019;19(Suppl 4):447.

25. GRANGER AS, HANGER HC. Olanzapine. Extrapyramidal side effects in the elderly. Aust NZ J Med. 1999;29(3):371-2.

26. Divac N, Prostran M, Jakovcevski I, Cerovac N. Second-generation antipsychotics and extrapyramidal adverse effects. Biomed Res Int. 2014;656370.

27. Soininen H. VLELExtrapyramidal signs in Alzheimer's disease. a 3-year followup study. J Neural Transm. 1992;(4):107-19.

28. Park JH, Myung W, Choi J, Kim S, Chung JW, Kang HS, Na DL, Kim SY, Lee J, Han S, et al. Extrapyramidal signs and cognitive subdomains in Alzheimer disease. Am J Geriatr Psychiatry. 2016;24(7):566-74

29. Wilson RS, Bennett DA, Gilley DW, Beckett LA, Schneider JA, Evans DA. Progression of parkinsonism and loss of cognitive function in Alzheimer disease. Arch Neurol. 2000;57(6):855-60.

30. Burns JM, Galvin JE, Roe CM, Morris JC, McKeel DW. The pathology of the substantia nigra in Alzheimer disease with extrapyramidal signs. Neurology. 2005:64(8):1397-403.

31. Li Z, Xiong Z, Manor LC, Cao H, Li T. Integrative computational evaluation of genetic markers for Alzheimer's disease. Saudi J Biol Sci. 2018;25(5):996-1002. 
32. Li H, Lv CL, Yang CS, Wei DF, Chen KW, Li SW, Zhang ZJ. SORL1 rs1699102 polymorphism modulates age-related cognitive decline and gray matter volume reduction in non-demented individuals. Eur J Neurol. 2017;24(1): 187-94.

33. Le Guennec K, Tubeuf H, Hannequin D, Wallon D, Quenez O, Rousseau S, Richard A, Deleuze J, Boland A, Frebourg T, et al. Biallelic loss of function of SORL1 in an early onset Alzheimer's disease patient. J Alzheimers Dis. 2018; 62(2):821-31.

34. Cuccaro ML, Carney RM, Zhang Y, Bohm C, Kunkle BW, Vardarajan BN, Whitehead PL, Cukier HN, Mayeux R, St GP, et al. SORL1 mutations in earlyand late-onset Alzheimer disease. Neurol Genet. 2016;2(6):e116.

35. Huang C, Liu M, Kao H, Chou K, Yang AC, Wang Y, Chen T, Tsai S, Lin C. Effect of Alzheimer's disease risk variant rs3824968 at SORL1 on regional gray matter volume and age-related interaction in adult lifespan. Sci Rep. 2016;6:23362.

36. Boublay N, Bouet R, Dorey JM, Padovan C, Makaroff Z, Fédérico D, Gallice I, Barrellon MO, Robert P, Moreaud O, et al. Brain volume predicts behavioral and psychological symptoms in Alzheimer's disease. J Alzheimers Dis. 2020. https://doi.org/10.3233/JAD-190612

\section{Publisher's Note}

Springer Nature remains neutral with regard to jurisdictional claims in published maps and institutional affiliations.

Ready to submit your research? Choose BMC and benefit from:

- fast, convenient online submission

- thorough peer review by experienced researchers in your field

- rapid publication on acceptance

- support for research data, including large and complex data types

- gold Open Access which fosters wider collaboration and increased citations

- maximum visibility for your research: over $100 \mathrm{M}$ website views per year

At $\mathrm{BMC}$, research is always in progress.

Learn more biomedcentral.com/submissions 